\title{
A logística dos sentidos
}

\author{
[David Mach, Incoming, \\ Griffin Gallery, Londres]
}

Helio Branco ${ }^{1}$

http://dx.doi.org/10.22409/poiesis.1931.221-226

A natureza exorbitante de um trabalho do artista escocês David Mach na Bienal de São Paulo, em 1984, enfrentava a amplidão envidraçada do Pavilhão Ciccilo Matarazzo com desenvoltura, potencialmente apto a enlaçar, além de objetos, o vasto espaço arquitetônico interno, circundado por sua vez por jardins e ciclovias: a duna de jornais e revistas que se erguia parecia ter sido esculpida pelo trator que a confrontava. Em outra oportunidade, em Londres, em 2017, na mostra individual Incoming na Griffin Gallery, efeitos dessa desmesura provocavam uma compressão no ambiente algo intensiva; a obra tornase presente de um modo que faz com que não possamos ficar ao largo do raio de influência do arranjo, pois ela demanda atenção e tem êxito, de maneira a um só tempo sutil e avassaladora. Um misto de "cumplicidade" e de "agressão" permeia o ambiente. Afora a

\footnotetext{
${ }^{1}$ Helio Antunes Branco é artista, Doutor e Mestre em Linguagens Visuais pelo Programa de Pós-Graduação em Artes Visuais da Escola de Belas Artes pela Universidade Federal do Rio de Janeiro. Possui graduação em Escultura na Escola de Belas Artes pela Universidade Federal do Rio de Janeiro (2002). É atualmente Professor Substituto de Pintura na Escola de Belas Artes - UFRJ. E-mail: heliobranco@yahoo.com.br
} 


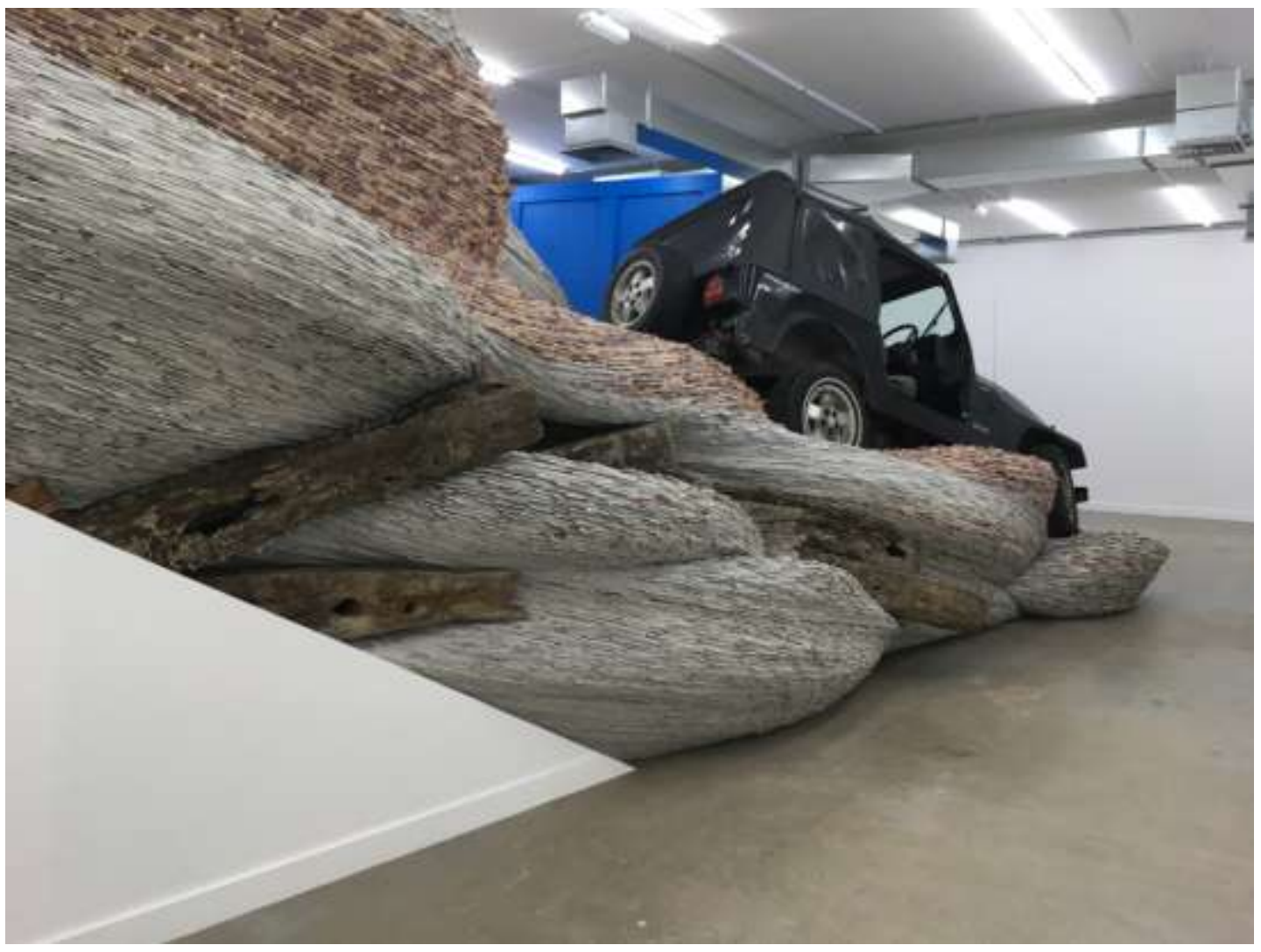

Poiésis, Niterói, v. 19, n. 31, jan./jun. 2018. 


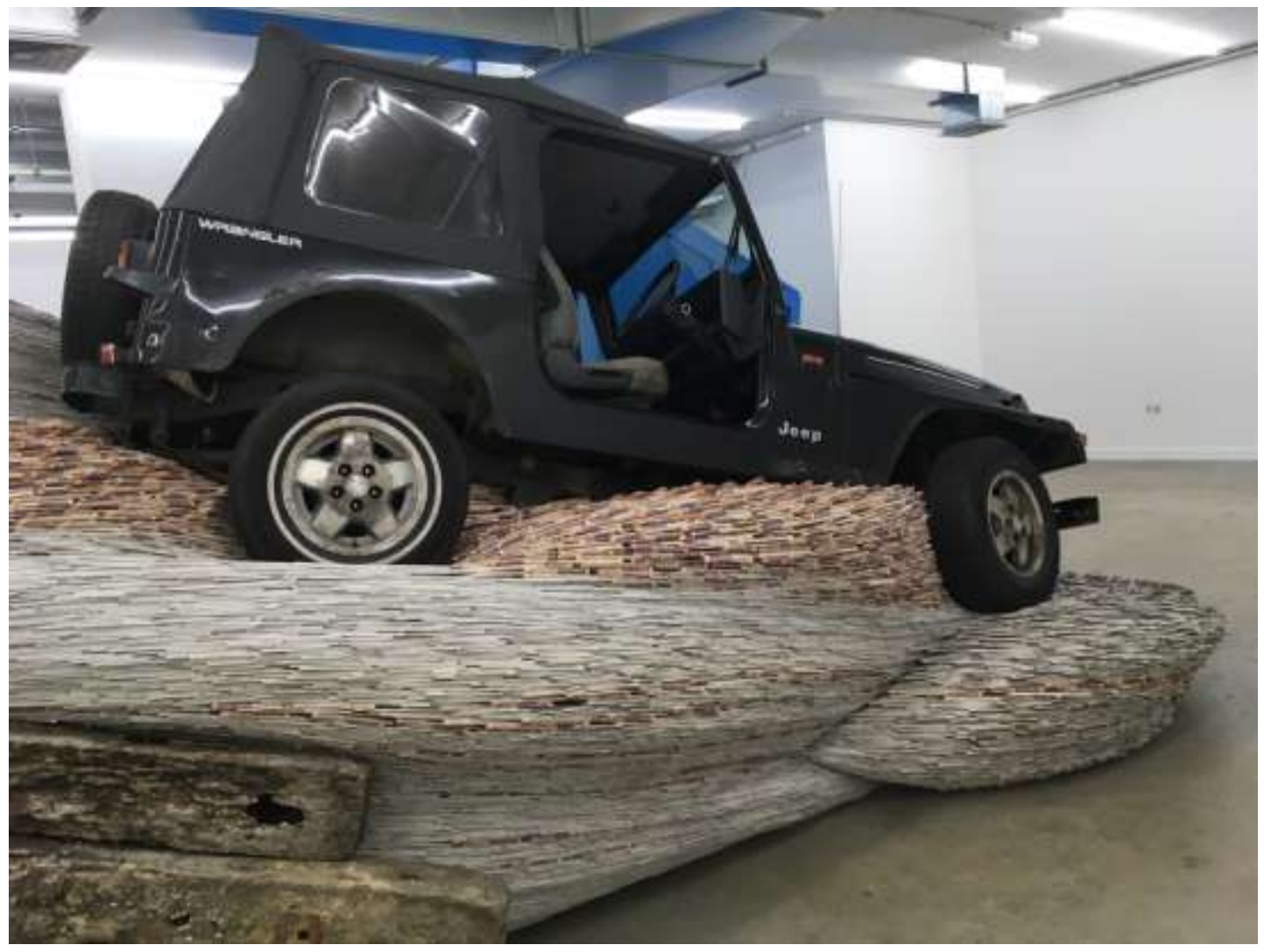

Poiésis, Niterói, v. 19, n. 31, jan./jun. 2018. 
grande concentração de matéria que modifica a acústica da sala e faz com seja possível percebermos nossos passos, vozes e o som do ambiente diferentemente. Por óbvio, não apenas a atmosfera é engolfada pela obra no que tange aos domínios da visão, mas também aos do olfato: óleo, tinta, borracha, papel; e aos do tato, que se conecta à visão incitado pela sugestão de superfícies.

De uma parede central desemboca uma avalanche composta por 20 toneladas de jornais e tabloides londrinos de colorações diversas; um automóvel utilitário de porte médio preto e brilhante; e, não tão maior que o veículo, um contêiner de cor azul intensa. A cascata de jornais, caprichosamente construída em volutas que se superpõem e se mesclam, avança de um portal praticamente camuflado na estrutura predial, de modo que é impossível circundar o trabalho e somos induzidos a movimentos em forma de $\mathrm{U}$ em torno da obra. A estrutura consuma uma ondulação agigantada de material industrial produzido em massa, reúne incontáveis unidades sem junção definitiva, aptas a serem reconfiguradas a qualquer tempo. O Jeep, que pertence a Mach e que ele veio dirigindo da Escócia, concebido para vencer terrenos acidentados com destreza e suportar cargas consideráveis, jaz acoplado sobre a montanha de "detritos" (assim o artista se refere aos impressos), obliquamente, vazio; ladeado pelo enigmático e impávido paralelepípedo azul, grande o suficiente para contê-lo, igualmente arremessado no turbilhão. Pares de grossas toras de madeira bruta, com mais de 2 metros de comprimento, tomam parte nesse arranjo e, a despeito de seu papel de arrimo, encontram-se tragadas pela torrente de papel tanto quanto os objetos aos quais dão sustentação: são os artefatos que mais explicitamente fazem convergir plasticidade e função ordinária, embora os outros componentes também o façam com menor intensidade.

No seio do literal deslizamento material da enxurrada, insinua-se um jogo de alternâncias de significado que faz oscilar os papéis de conteúdo e de continente dos volumes, enquanto também se esboça a noção de um tipo de autossuficiência operacional latente, como se à obra fosse factível portar-se, trazer-se ou levar-se a si mesma, e por si mesma, ou seja, movimentar tudo aquilo de que depende para constituir-se.

Poiésis, Niterói, v. 19, n. 31, jan./jun. 2018. 
É interessante notar que a latência da propensão ao movimento, resolvida como logística da matéria, e o revezamento de sentido nos grandes volumes unitários, por exemplo, mas não só neles, permeiam Incoming no todo. De modo que os acúmulos de material industrializado, característicos do trabalho de Mach, podem ser experimentados diferentemente de seu efeito epidérmico mais evidente. Observe-se também que não é essencial estabelecer compromissos participativos ao lado da fruição da obra, que obras como as do Atelier Van Lieshout, também apoiadas na logística, tentam manter.

Talvez não seja ocioso situar Incoming no âmbito de ação da Griffin Gallery. A galeria oferece um programa de residência artística, um fluxograma de exposições e um prêmio anual, integrados a uma plataforma de fomento mais ampla, STEAM Co. (Science, Technology, Engineering and Maths), interessada em inovação e desenvolvimento, mesclando práticas artísticas e educação, voltada para a formação de público, abrangendo a comunidade do entorno da galeria, especialmente crianças. Seu programa de residências, aberto a artistas do mundo todo, possui dois módulos que, de modos diferentes, estão voltados para pesquisas de materiais artísticos. O complexo funciona situado em alojamentos nas vizinhanças da galeria e conta com dois estúdios no mesmo prédio que a acolhe. O projeto é comissionado e tem suporte técnico da Windsor \& Newton, Liquitex e Conté à Paris, agrupadas por sua vez na Colart, holding de empresas do setor que acredita que o engajamento no material artístico seja crucial no ato criativo da arte de nossos dias. O fluxograma de exposições articula-se de maneira diversa às residências. O prêmio anual de pintura e desenho é conferido a trabalhos percebidos como inovadores nesse segmento, sejam de laboratório, projetos em andamento ou exposições propriamente ditas.

Premiado com o Turner Prize em 1988, não é difícil traçar a conexão de David Mach nessa rede que envolve pesquisa, produção, ensino e fomento, como eco de sua própria formação, mestre pela Royal College of Art e doutor pela University of Dundee, e como decorrência de suas atividades docentes como professor de escultura na Royal Academy School of London. 


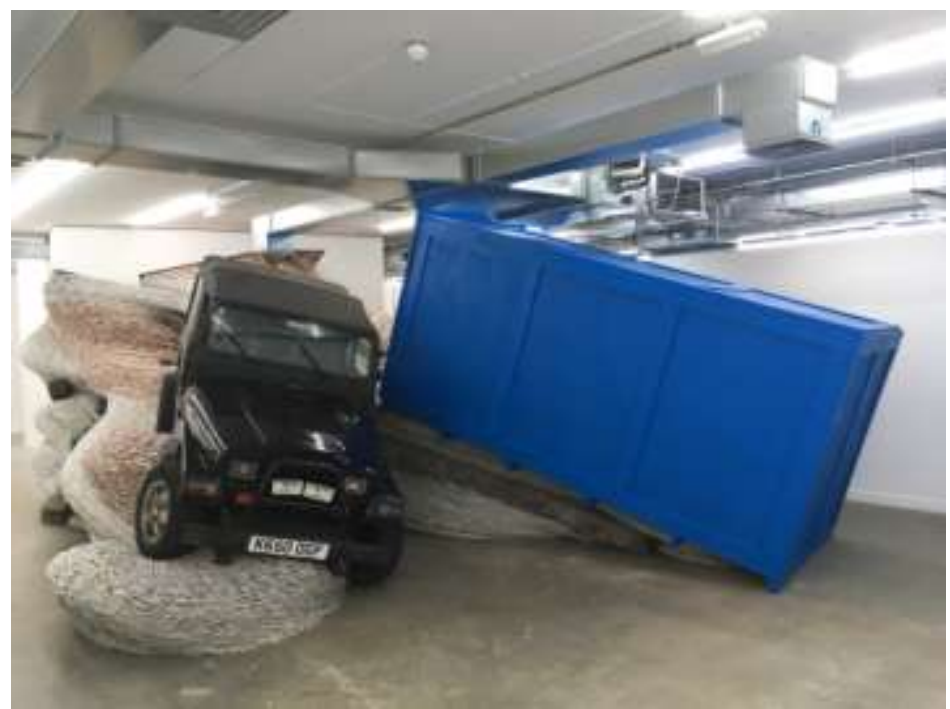

David Mach, Incoming

de 11 de maio a 17 de julho de 2017

Griffin Gallery, Londres

Mais informações: http://griffingallery.co.uk/exhibitions/david-mach

(Fotos: Helio Branco)

Recebido: 15/5/2018; Aprovado: 29/5/2018

Como citar: BRANCO, Helio. A logística dos sentidos [resenha crítica da mostra de David Mach, Incoming, Griffin Gallery, Londres]. Poiésis, Niterói, v. 19, n. 31, p. 221-226, jan./jun. 2018.

doi: http://dx.doi.org/10.22409/poiesis.1931.221-226

Poiésis, Niterói, v. 19, n. 31, jan./jun. 2018. 